\title{
Bilateral bifid mandibular canal: a case report using cone beam computed tomography
}

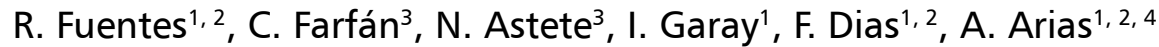 \\ ${ }^{1}$ Department of Integral Adults Dentistry, Dental School, Universidad de La Frontera, Temuco, Chile \\ ${ }^{2}$ Research Centre in Dental Sciences (CICO), Dental School, Universidad de La Frontera, Temuco, Chile \\ ${ }^{3}$ Master's Programme in Dentistry, Dental School, Universidad de La Frontera, Temuco, Chile \\ ${ }^{4}$ Universidad Adventista de Chile, Chillán, Chile
}

[Received: 19 January 2018; Accepted: 22 February 2018]

\begin{abstract}
The mandibular canal (MC) originates in the mandibular foramen and runs bilaterally through the mandibular ramus and body, ending in the mental foramen. One of the most common anatomical variations is bifid MC, the configurations of which have been classified into four categories and sub-categories. The prevalence of these variations depends on the imaging method used. Studies carried out in panoramic $X$-rays and cone beam computed tomography (CBCT) show prevalences varying between $1 \%$ and $20 \%$. In this case report we present the finding of a bilateral bifid MC by CBCT examination; we describe its location and morphological characteristics. The variation found was a type 1 bilateral bifid MC, which consists in an accessory canal originating from a single mandibular foramen and extending to the third molar or its immediate surroundings. In this report we discuss the importance of detecting these anatomical variations, as well as their implications in clinical practice. (Folia Morphol 2018; 77, 4: 780-784)
\end{abstract}

Key words: mandibular canal, anatomical variation, bifid canal, cone beam computed tomography

\section{INTRODUCTION}

The mandibular canal (MC) is a bilateral structure which originates in the mandibular foramen and runs longitudinally along the mandible towards the medial face of the ramus, relating in its course with the roots of the inferior molars and premolars and ending at the mental foramen $[11,22,27]$. It contains the inferior alveolar vasculo-nervous bundle [12], which is responsible for the somatosensory activity and the irrigation of the mandibular teeth, interdental papilla, lip and osseous alveolar tissue $[1,14]$. One of the most studied variants of the MC is the bifid MC. Like the trifid variant, its formation is explained by embryonic development around the seventh week of gestation, when the inferior alveolar nerve presents as three independent nerve branches surrounded by osseous tissue $[7,16]$. If fusion of one or more of these nerve branches during development is incomplete, and the surrounding tissue becomes ossified, an accessory $M C$ results $[5,7,16]$. It has been reported that the presence of this new MC may be accompanied by one or more accessory foramina, depending on where the accessory canal terminates, with cases being found close to the mental foramen [9], vestibular and/or lingual of the bone plates or in a retromolar position [15].

Bifid MC is classified into four types: type I or retromolar, type II or dental, type III or anterior, type IV or buccolingual $[3,14]$. Type I or retromolar is a branch extending from the principal MC under the third molar, ending in a retromolar foramen [19]. Histological studies in cadavers have reported this 


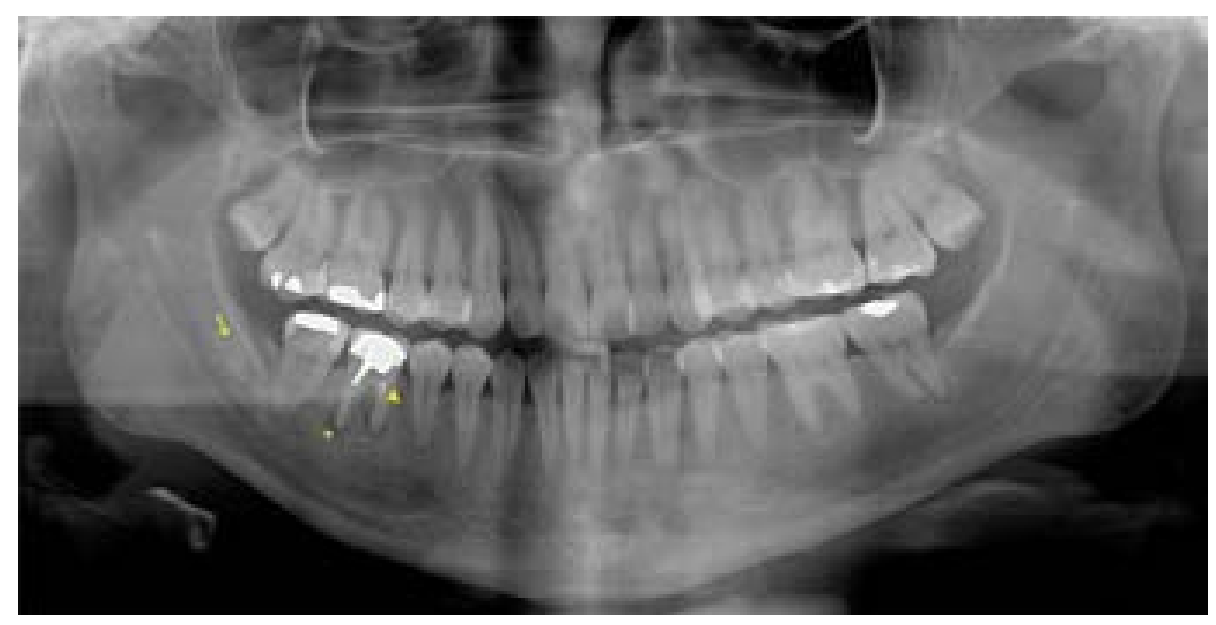

Figure 1. Initial digital panoramic $X$-ray of the patient showing a radiolucent area compatible with apical granuloma $\left(^{*}\right)$ related with the dental apices of tooth 4.6 (right mandibular first molar) and incomplete endodontic treatment (arrowhead) of the mesial root. Indications of bifid mandibular canal can be observed in the right retromolar zone (arrow).

variant, describing the presence of a neurovascular bundle in its interior which would innervate the buccinator muscle, retromolar trigone, inferior third molars, bone, mucus and jaw in the zone $[2,3,8]$. Thus knowledge of the location and morphology of this variant is essential for planning treatments like mandibular osteotomies, dental implants and extractions of the third molar $[4,20,23]$; in the latter treatment the reported incidence of damage to the inferior alveolar nerve is $0.4-13.4 \%$ [6]. This report describes the finding of a bilateral type I bifid MC, which was explored using digital panoramic $\mathrm{X}$-ray and in-depth analysis by cone beam computed tomography (CBCT). The use of this three-dimensional (3D) examination produced morphometric data which we could compare with those reported in the literature.

\section{CASE REPORT}

Female patient aged 31 years attended a private dental clinic in Temuco, Chile, reporting pain related with tooth 4.6 (right mandibular first molar) in which a single fixed prosthesis had been installed a few months earlier. During clinical examination, the patient reported no current systemic diseases, and no history of serious disease. When the digital panoramic X-ray was examined, a radiolucent area was observed related with the dental apices of tooth 4.6, compatible with apical granuloma and incomplete endodontic treatment of the mesial root (Fig. 1). Furthermore, indices of the presence of a bifid $\mathrm{MC}$ were observed in the right retromolar zone. After clinical and radiological examination it was determined that the treatment prognosis for the tooth was bad, and it was therefore decided to carry out an extraction and subsequently install a dental implant.

For surgery planning purposes and to confirm the suspicion of a bifid MC in the right retromolar zone, CBCT of the mandibular area was requested with viewing field $12 \times 9 \mathrm{~cm}$ and voxel size $0.2 \mathrm{~mm}(120 \mathrm{kV}$, $10 \mathrm{~mA}, 24 \mathrm{~s}$ acquisition time). The examination was carried out in the Imaging Service of the Clínica Odontológica Docente Asistencial (CODA), Universidad de La Frontera, using a PAX Zenith 3D machine (Vatech Co., Gyeonggi-Do, Korea). The examination confirmed the presence of a bilateral bifid MC (Fig. 2), with bifurcations in the retromolar zone in an area immediate to the vestibular cortical layer of the bone, while the emergence of the accessory canal was between the internal and external oblique lines of the mandible (Fig. 3). The approximate length of the accessory canal was $8.8 \mathrm{~mm}$ on the right side and $12.5 \mathrm{~mm}$ on the left.

\section{DISCUSSION}

Anatomical variations in the mandible, both of the $\mathrm{MC}$ and its foramina, may cause complications in surgical procedures if they are not identified properly and in time. Various authors indicate the importance of $\mathrm{CBCT}$ for detecting these canals, and stress early identification to reduce complications such as haemorrhage, altered sensation, swelling and pain $[12,13]$ in medical and dental procedures $[14,26]$. Furthermore, it must be remembered that when these canals present bilaterally, both the canals and the foramina are generally symmetrical $[25,28]$, which agrees with observations in our case. 


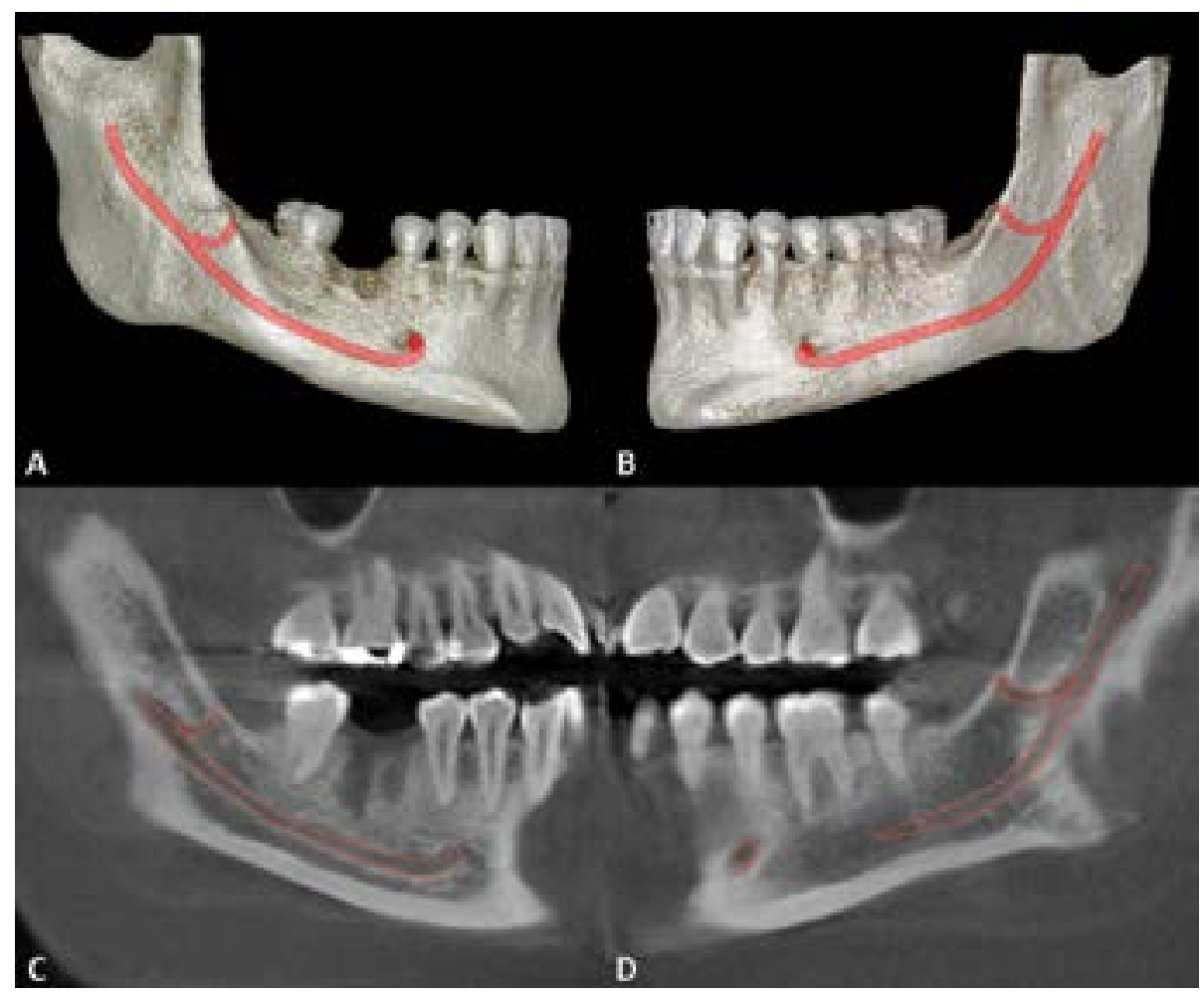

Figure 2. Bilateral bifid mandibular canal (red). Side view of the three-dimensional reconstruction of the right (A) and left (B) sides of the mandible. Sagittal radiographic view of the right (C) and left (D) sides of the mandible.

The prevalence of bifid $\mathrm{MC}$ reported in the literature varies, since it depends on the imaging method used for identification. The first studies done using panoramic X-rays date from 1977 [17]; an average of $4000 \mathrm{X}$-rays per year were examined up to 2003 [24], with a reported incidence of around $1 \%$ [17, $18,24,29]$. This figure has increased with technological improvements and the introduction of CBCT. In 2009, Naitoh et al. [14] carried out a study of 122 patients who needed dental implant, using computed tomography $(\mathrm{CT})$ and $\mathrm{CBCT}$, in which they observed the prevalence of bifid $M C$ and its four variants. CBCT detected $65 \%$ prevalence of bifid MC in general, with type I accounting for $29.8 \%$. CBCT proved to be more effective in detecting bifid MC, since of the 19 bifid canals found, 4 were not detected by CT. In 2014, Kang et al. [10] assessed the prevalence of bifid MC in Korea through an analysis of 1933 CBCT records, finding a prevalence of $10.2 \%$. They also found that type I was the most recurrent with $52.5 \%$ of the cases. In 2014, Rashsuren et al. [21] using CBCT indicated a prevalence of $22.6 \%$ bifid MC, and as in the other studies, type I was the most frequent with $71.3 \%$ of cases. Although no consensus can be reached on the prevalence of bifid MC, all the studies agree that more cases are found when the analysis is done by $C B C T$ than by panoramic $X$-ray, since the high resolution of the former method allows very narrow accessory canals and their bifurcations to be detected. However, the prevalence reported using this type of examination varies greatly, which can be explained by the sample size, the criteria used for determining the classification, calibration, number of examiners and ethnic group of subjects. When the ratios between the presence of bifid $M C$ and variables such as the sex or age of the subjects are analysed, there is a certain degree of consensus in the literature that no significant differences exist [3, 17].

Various authors have studied the diameter and mean length of the accessory canal. In 2014, Kang et al. [10] analysed CBCT records of 1933 patients taken prior to the extraction of impacted third molars, of which 198 cases presented bifid MC. They reported that the mean diameter was $1.21 \mathrm{~mm}(1.36 \mathrm{~mm}$ in the case of type I). The mean length of the accessory canal was $14.97 \mathrm{~mm}, 16 \mathrm{~mm}$ for type I. Another study reported similar mean values, with diameter $2.2 \mathrm{~mm}$, no significant differences between types, and mean length $16.9 \mathrm{~mm}$ [21]. A study using CT reported a diameter of 1 to $2 \mathrm{~mm}$ and length of $15 \mathrm{~mm}$ for the 


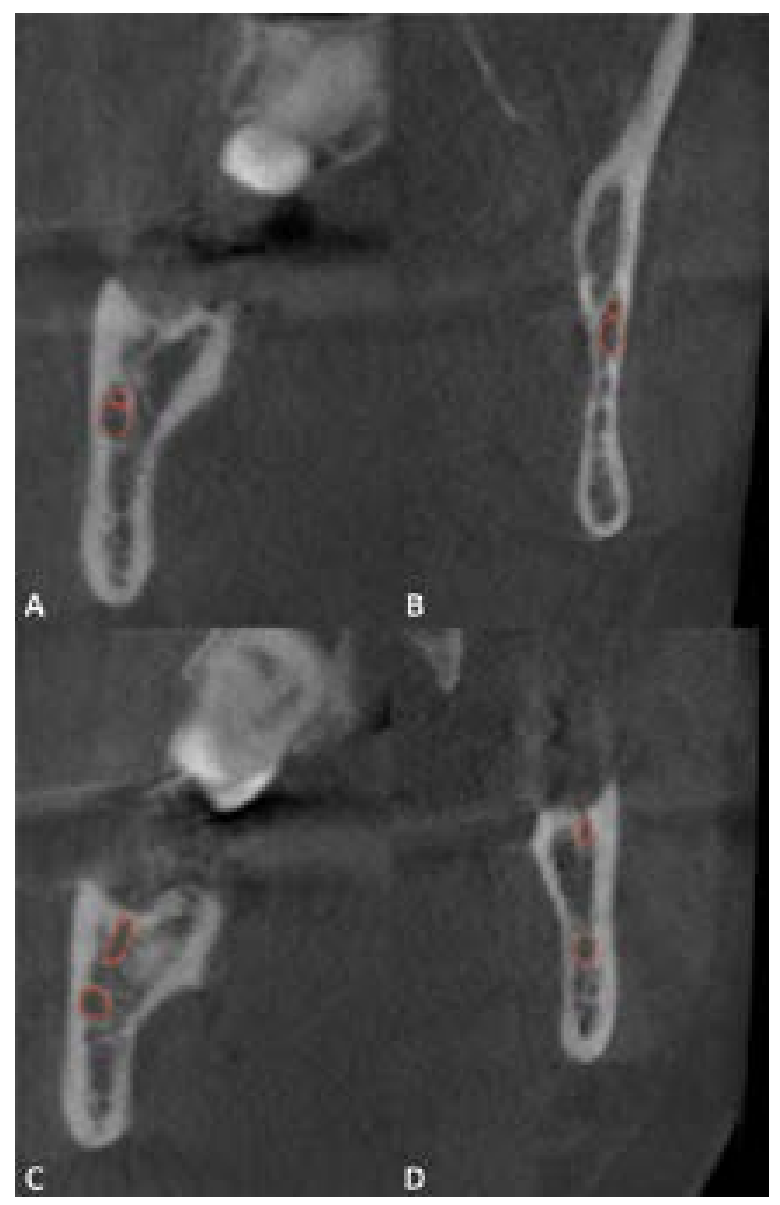

Figure 3. Coronal section of the bifurcation zone (retromolar zone) of the bifid mandibular canal on the right (A) and left (B) sides of the mandible. Coronal section of the emergence zone of the accessory canal (between the internal and external oblique lines) of the right (C) and left (D) sides of the mandible.

accessory canal [11]. The measurements reported, which are slightly larger than the characteristics of the canal in our case, may vary according to the ethnic group of the study subjects.

\section{CONCLUSIONS}

Today there are very few reports being published on anatomical variations of the MC, and fewer still case reports of bilateral type I canals. This may be explained by the low prevalence and because the majority of the studies which exist are based on panoramic $X$-rays. There would appear to be a need for a larger number of CBCT studies reporting the prevalence and morphometric indicators of the accessory canals and their different types in Latin populations, since most of the studies reported are of Asian or North American populations. Of all the alternative imaging methods available to clinicians, CBCT appears to be the best for assessing the MC, since it provides a better view of the adjacent structures, allowing assessment of the morphology. This is very important for the planning of complex treatments such as dental implants and extraction of third molars; it is therefore recommended that procedures of this kind in the mandibular zone should not be carried out without establishing the position and possible anatomical variations of the MC.

\section{REFERENCES}

1. Akhtar MJ, Parveen S, Madhukar PK, et al. et al.. A morphological study of retromolar foramen and canal in indian dried mandibles. J Evolution Med Dent Sci. 2014; 3: 13142-13151.

2. Anderson LC, Kosinski TF, Mentag PJ. A review of the intraosseous course of the nerves of the mandible. J Oral Implantol. 1991; 17(4): 394-403, indexed in Pubmed: 1813647.

3. Bilecenoglu B, Tuncer N. Clinical and anatomical study of retromolar foramen and canal. J Oral Maxillofac Surg. 2006; 64(10): 1493-1497, doi: 10.1016/j. joms.2006.05.043, indexed in Pubmed: 16982307.

4. Castro MA, Lagravere-Vich MO, Amaral TM, et al. Classifications of mandibular canal branching: A review of literature. World J Radiol. 2015; 7(12): 531-537, doi: 10.4329/ wjr.v7.i12.531, indexed in Pubmed: 26753068.

5. Chávez-Lomeli ME, Mansilla Lory J, Pompa JA, et al. The human mandibular canal arises from three separate canals innervating different tooth groups. J Dent Res. 1996; 75(8): 1540-1544, doi: 10.1177/00220345960750080401, indexed in Pubmed: 8906121.

6. Cheung LK, Leung YY, Chow LK, et al. Incidence of neurosensory deficits and recovery after lower third molar surgery: a prospective clinical study of 4338 cases. Int J Oral Maxillofac Surg. 2010; 39(4): 320-326, doi: 10.1016/j. ijom.2009.11.010, indexed in Pubmed: 20061121.

7. Das S, Suri RK. An anatomico-radiological study of an accessory mandibular foramen on the medial mandibular surface. Folia Morphol. 2004; 63(4): 511-513, indexed in Pubmed: 15712153.

8. Fukami K, Shiozaki K, Mishima A, et al. Bifid mandibular canal: confirmation of limited cone beam $C T$ findings by gross anatomical and histological investigations. Dentomaxillofac Radiol. 2012; 41(6): 460-465, doi: 10.1259/ dmfr/60245722, indexed in Pubmed: 22116121.

9. Garay I, Cantín M. Accessory mental foramina assessed by cone-beam computed tomography: report of unilateral and bilateral detection. Int J Morphol. 2013; 31(3): 1104-1108, doi: 10.4067/s0717-95022013000300052.

10. Kang JH, Lee KS, Oh MG, et al. The incidence and configuration of the bifid mandibular canal in Koreans by using cone-beam computed tomography. Imaging Sci Dent. 2014; 44(1): 53-60, doi: 10.5624/isd.2014.44.1.53, indexed in Pubmed: 24701459.

11. Kaufman E, Serman NJ, Wang PD. Bilateral mandibular accessory foramina and canals: a case report and review of the literature. Dentomaxillofac Radiol. 2000; 29(3): 170-175, doi: 10.1038/sj/dmfr/4600526, indexed in Pubmed: 10849544.

12. Kim ST, Hu KS, Song WC, et al. Location of the mandibular canal and the topography of its neurovascular structures. 
J Craniofac Surg. 2009; 20(3): 936-939, doi: 10.1097/ SCS.0b013e3181a14c79, indexed in Pubmed: 19461335.

13. Misch CE, Crawford EA. Predictable mandibular nerve location--a clinical zone of safety. Int J Oral Implantol. 1990; 7(1): 37-40, indexed in Pubmed: 2103117.

14. Naitoh $M$, Hiraiwa $Y$, Aimiya $H$, et al. Observation of bifid mandibular canal using cone-beam computerized tomography. Int J Oral Maxillofac Implants. 2009; 24(1): 155-159, indexed in Pubmed: 19344041.

15. Naitoh M, Nakahara K, Hiraiwa $Y$, et al. Observation of buccal foramen in mandibular body using cone-beam computed tomography. Okajimas Folia Anat Jpn. 2009; 86(1): 25-29, indexed in Pubmed: 19522303.

16. Narayana K, Prashanthi N. Incidence of large accessroy mandibular foramen in human mandibles. Eur J Anat. 2003; 7: 139-141.

17. Nortjé CJ, Farman AG, Grotepass FW. Variations in the normal anatomy of the inferior dental (mandibular) canal: A retrospective study of panoramic radiographs from 3612 routine dental patients. Br J Oral Surg. 1977; 15(1): 55-63, doi: 10.1016/0007-117x(77)90008-7.

18. Langlais RP, Broadus R, Glass BJ. Bifid mandibular canals in panoramic radiographs. J Am Dent Assoc. 1985; 110(6): 923-926, indexed in Pubmed: 3860553.

19. Ossenberg NS. Temporal crest canal: case report and statistics on a rare mandibular variant. Oral Surg Oral Med Oral Pathol. 1986; 62(1): 10-12, indexed in Pubmed: 3523363.

20. Ozturk A, Potluri A, Vieira AR. Position and course of the mandibular canal in skulls. Oral Surg Oral Med Oral Pathol Oral Radiol. 2012; 113(4): 453-458, doi: 10.1016/j. tripleo.2011.03.038, indexed in Pubmed: 22676925.

21. Rashsuren O, Choi JW, Han WJ, et al. Assessment of bifid and trifid mandibular canals using cone-beam computed tomography. Imaging Sci Dent. 2014; 44(3): 229-236, doi: 10.5624/isd.2014.44.3.229, indexed in Pubmed: 25279344.

22. Reiser GM, Manwaring JD, Damoulis PD. Clinical significance of the structural integrity of the superior aspect of the mandibular canal. J Periodontol. 2004; 75(2): 322-326, doi: 10.1902/jop.2004.75.2.322, indexed in Pubmed: 15068122.

23. Renton T, Dawood A, Shah A, et al. Post-implant neuropathy of the trigeminal nerve. A case series. Br Dent J. 2012; 212(11): E17, doi: 10.1038/sj.bdj.2012.497, indexed in Pubmed: 22677874.

24. Sanchis JM, Peñarrocha M, Soler F. Bifid mandibular canal. J Oral Maxillofac Surg. 2003; 61 (4): 422-424, doi: 10.1053/ joms.2003.50004, indexed in Pubmed: 12684957.

25. Schejtman R, Devoto FC, Arias NH. The origin and distribution of the elements of the human mandibular retromolar canal. Arch Oral Biol. 1967; 12(11): 1261-1268, indexed in Pubmed: 5234232.

26. Silva FM, Cortez AL, Moreira RW, et al. Complications of intraoral donor site for bone grafting prior to implant placement. Implant Dent. 2006; 15(4): 420-426, doi: 10.1097/01.id.0000246225.51298.67, indexed in Pubmed: 17172961.

27. Suazo GIC, Morales HCA, Cantín LMG, et al. Aspectos biométricos del canal mandibular. Int J Morphol. 2007; 25(4): 811-816, doi: 10.4067/s0717-95022007000400021.

28. Sutton RN. The practical significance of mandibular accessory foramina. Aust Dent J. 1974; 19(3): 167-173, indexed in Pubmed: 4530720.

29. Zografos J, Kolokoudias M, Papadakis E. [The types of the mandibular canal]. Hell Period Stomat Gnathopathoprosopike Cheir. 1990; 5(1): 17-20, indexed in Pubmed: 2130051. 